\title{
Distomolars: An overview and 3 case reports
}

\author{
Naji Ziad Arandi* \\ Department of Conservative Dentistry and Prosthodontics, The Arab American University, Palestine
}

\begin{abstract}
A distomolar is a supernumerary tooth which is located distal to third molars. They appear more frequently in men than in women. Several theories had been suggested to explain this phenomenon with the "dental lamina hyperactivity theory" to be the most accepted. Supernumerary molars (distomolars) are usually impacted. They can be associated with complications or stay asymptomatic. Radiographic identification of distomolars is very important for detection of asymptomatic impacted distomolars. Treatment involves the removal of the distomolar because of the complications that their presence may cause or to keep under observational management. This article presents an overview of distomolars and reports 3 cases of distomolars in patients who attended to our clinic.
\end{abstract}

\section{Introduction}

A supernumerary tooth is one that is additional to the normal series and can be found in almost any region of the dental arch [1] Supernumerary teeth can be mainly classified according to morphology (form) and location in the dental arches. According to their locations, supernumeraries may be categorized into four types: Mesiodens, paramolar, distomolar, and parapremolar and into two types according to their morphology (form) rudimentary and supplemental. Rudimentary teeth (dysmorphic) defines teeth of abnormal shape and smaller size; including conical, tuberculate, and molariform types while supplemental teeth (eumorphic) are of normal shape and size resembling a particular tooth from the normal dentition $[1,2]$.

A distomolar is a supernumerary tooth which is located distal to third molars. A paramolar is a supernumerary tooth situated lingually or buccally to a molar tooth [3]. Distomolars along with paramolars are also known as fourth molars. A distomolar can have a normal morphology with a completely developed crown, single root and distinct from the adjacent third molar or it can differ from its normal morphology. Distomolars can erupt fully and align themselves in the dental arch or they can show partial or complete impaction [4]. A study by Kurt, et al. [5] found that $92.7 \%$ of 55 distomolars found in thier study populationwere impacted. Another study by Arslan, et al. [6] found that $20(69 \%)$ out of the 29 distomolars found in the study population were impacted. Kaya, et al. [7] found that $83.3 \%$ of the 30 distomolars observed in their study population $(n=10111)$ were impacted. Casettee, et al. [4] reported that only 3 out 24 distomolars observed in 25186 Italian Caucasian patients were impacted while the others erupted.

Distomolars are either eumorphic or dysmorphic in shape [49]. Studies report a major percentage of distomolars in their studies molariform (tuberculated) in shape [5,9]. On the other hand, studies report that distomolars are mainly peg-and conical shaped and smaller than the maxillary third molar [4,7]. Arslan and his colleagues [6] reported that the distomolars they observed exhibited three different forms: a premolar shape with one root, a premolar shape with only a crown and no root, and a rudimentary conical shape.

Various studies aimed to evaluate the prevalence and characteristics of distomolars in different populations. The prevalence of distomolars among study population has been reported in the range of $0.03 \%-2.1 \%$
[4-7,9-11]. Thomas, et al. [9] investigated the presence of distomolars in 1000 panoramic radiographs of Indian patients in Kerala. They found distomolars in 21 radiographs (12 males and 9 females) giving a total prevalence of $2.1 \%$. Kurt, et al. [5] conducted a retrospective observational study on 14250 Turkish patients and reported the presence of distomolars in $0.32 \%$ of this population. The distomolar prevalence of $0.21 \%$ was reported by a retrospective analysis that was carried out on an initial sample of 104,902 subjects drawn from the panoramic $\mathrm{x}$-rays files from 10 clinics in 7 Turkish cities [8]. Arslan, et al. [6] investigated the presence of distomolars in 4023 Turkish patients, their study reported that the frequency of distomolars was $0.57 \%$. Kaya, et al. [7] studied the prevalence and characteristics of non-syndromic distomolars and reported that distomolars were observed in $0.26 \%$ of the investigated population $(\mathrm{n}=10111)$. Gopakumar, et al. [10] investigated the prevalence of supernumerary molar teeth in 11141 Indian patients. The findings of their study indicate that the prevalence of distomolars was $0.03 \%$. The difference in prevalence may be due to the racial difference among study populations.

Distomolars have male predilection $[5,7,9]$ and frequently located in the maxilla in both genders [5,7]. In the maxilla, distomolars occur with almost equal frequency in the left and right quadrants $[6,7,11]$. Thomas, et al. [9] observed that distomolar were more common on the right side of the maxilla [9]. In the mandible, distomolars were reported to also occur with almost equal frequency in the left and right quadrants [9,11]. Yet Arslan and his colleagues [6] reported distomolars more common on the left side of the mandible. Bilateral cases of distomolars are rare. Kaya, et al. [7] reported two cases out of 10111 patients to have bilateral maxillary distomolars and one case to exhibit distomolars bilaterally in the mandible and left maxilla. Kurt, et al. [5] reported nine out of 14250 cases to have maxillary bilateral distomolars $(0.063 \%)$ and they reported no cases in the mandible. Arslan, et al. [6] reported 2 out

Correspondence to: Naji Ziad Arandi, Assistant Professor, Department of Conservative Dentistry and Prosthodontics, The Arab American University, Palestine, Tel: 00972598126111, E-mail: naji.arandi@aauj.edu

Key words: supernumerary teeth, hyperdontia, distomolar, fourth molar

Received: August 06, 2017; Accepted: August 25, 2017; Published: August 28, 2017 
4,023 Turkish patients to have bilateral maxillary distomolars (0.049\%) and only one case to have bilateral mandibular distomolars.

The aim of this article is to present an overview on supernumerary molars (distomolars) and to reports three different cases and the possible treatment options.

\section{Case report 1}

A 31-year-old female visited a private dental clinic with the chief complaint of pain on the right side of the mandible. The familial, medical, and dental histories were examined, and nothing relevant was reported. An extra-oral examination did not reveal any abnormality. The intraoral examination of the permanent dentition in the maxillary and mandibular arches revealed the presence of a faulty amalgam restoration on the mandibular second premolar on the right side. Pain on percussion was present and the panoramic radiograph revealed RCT on the right mandibular second premolar with a periapical radiolucency surrounding the root. Incidentally, a supernumerary tooth was noticed on the right and the left side of the maxillary arch distally to 1 and 32 (Figure 1). Both maxillary distomolars were vertically impacted and much smaller than the adjacent third molar teeth. Clinically, there was no evidence of their presence. The patient had no complaint about this situation. The patient was informed about the condition and chose not to extract the distomolars.

\section{Case report 2}

A 29-year-old male patient, attended a private dental clinic to extract the remaining roots of the lower left mandibular first molar. Patient's medical and family histories were not significant and she did not have syndromic features. The panoramic x-ray incidentally revealed bilateral existence of a distomolar in the left and right sides of the mandible distal to tooth 17 and 32 (Figure 2). Management approach consisted of extraction of the left and right distomolar as it was slightly compromising the adjacent periodontal health.

\section{Case report 3}

A 29-year old healthy female reported with a chief complaint of pain on the left side of the lower jaw. On clinical examination, deep caries was present on the permanent lower left second molar. The panoramic $\mathrm{x}$-ray revealed the presence of an impacted distomolar on right side of the maxilla (Figure 3). The distomolar was asymptomatic and it was kept under observation as the patient was not willing for its treatment.

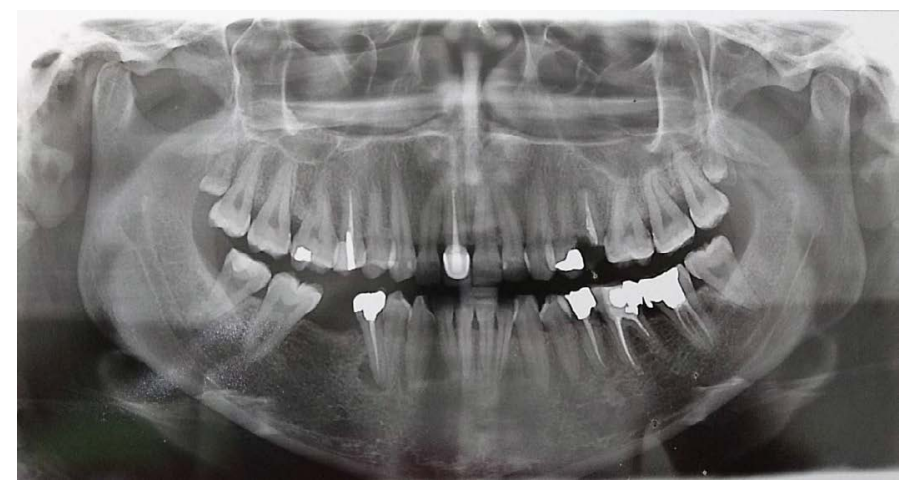

Figure 1. Panoramic radiograph with distomolars on the right and left sides of the maxillary arch.

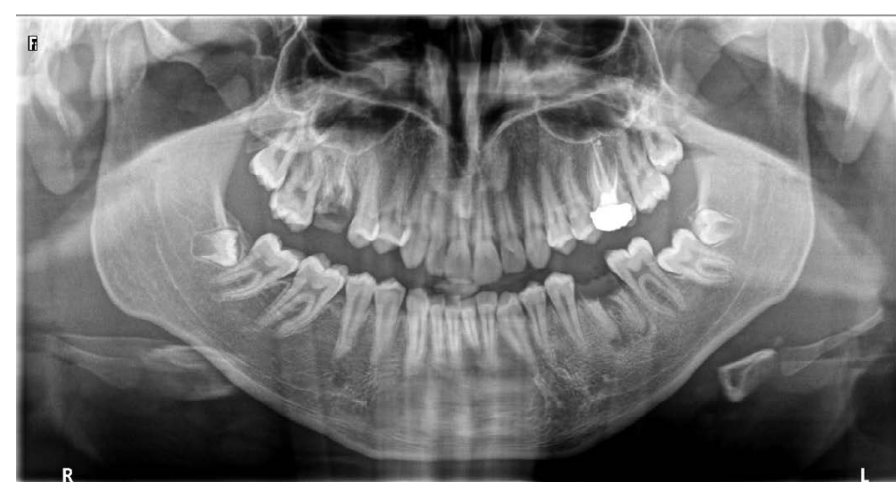

Figure 2. Panoramic radiograph with distomolars on the right and left sides of the mandibular arch.

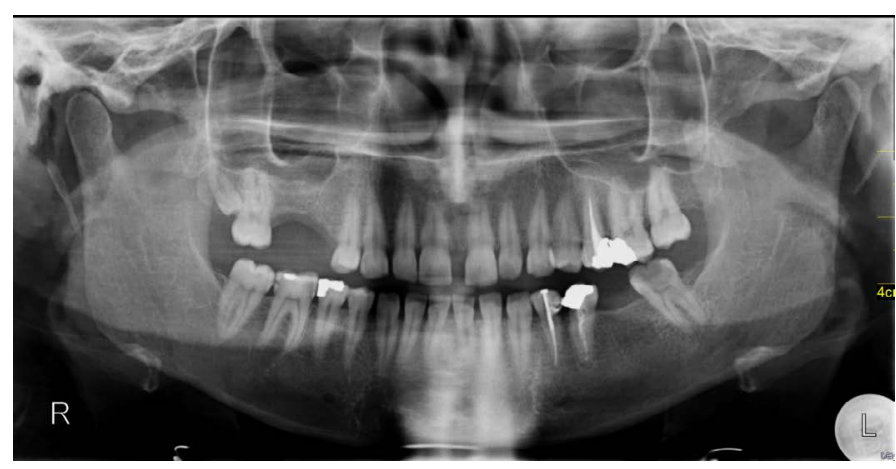

Figure 3. Panoramic radiograph with a distomolar on the right quadrant of the maxillary arch.

\section{Discussion}

The etiology of supernumerary teeth is not clearly understood. A number of theories have been formulated to describe the etiology of supernumerary teeth; these include the atavism theory, dichotomy theory, and dental lamina hyperactivity theory. The atavism theory suggests that the development of supernumerary teeth is a result of phylogenetic reversion to extinct primates with three pairs of incisors. The dichotomy theory suggests that they are a result of a dichotomy of the tooth bud, resulting into two equal or different-sized parts, resulting in the formation of two teeth of equal size, or one normal and one dysmorphic tooth, respectively. However, the most accepted theory is the dental lamina hyperactivity theory which suggests that they are formed as a result of local, independent, conditioned hyperactivity of the dental lamina. However, the role of complex interactions among a variety of environmental and genetic factors has been postulated $[2,12]$.

Clinical and radiographic identification of all the teeth is very important for an early detection of supernumerary teeth. Early intervention that enhances the therapeutic results. However, it may be difficult to formulate an ideal treatment plan for all cases with supernumerary teeth. But an effort can definitely be made. Radiographs are the most reliable and definite method for the diagnosis of unerupted supernumerary teeth. A panoramic radiograph is the most useful screening radiograph for these cases, as it shows all areas of the maxilla and mandible. New imaging techniques such as CBCT enables us to accurately evaluate the intraosseous location, inclination, and morphology of impacted supernumerary teeth [2].

In most cases, undiscovered fourth molar does not cause any complications within the dental arch or oral cavity. If distomolars are impacted they may cause complications such as impaction, root 
resorption or pulp necrosis of the adjacent tooth, pain in the molar area, infection, formation of diastema, follicular cyst, neoplasms, and neuralgias of the trigeminal nerve. In case they erupt they may cause malocclusion, retention or ectopic eruption, delayed eruption of the adjacent teeth, mandibular disorders, periodontal disease and caries $[2,3,13]$.

The treatment of distomolars teeth is still controversial - extraction or observational management. Treatment depends on the location of the supernumerary tooth and also on its potential adverse effect on adjacent hard and soft tissue structures. Extraction of a distomolar is indicated when any of the aforementioned complications is present. These supernumerary teeth may be kept under observation without extraction when there are no symptoms associated with them. If extraction is indicated, it should be done carefully to prevent any damage (ankylosis and maleruption) to the adjacent permanent teeth, to prevent any damage to nerve and blood vessels, and to prevent fracture of the maxillary tuberosity. Sometimes distomolars may be fused with the adjacent tooth structure which may make extraction difficult.

\section{Conclusion}

Although the frequency of distomolars is low, early diagnosis and treatment are important to minimize or prevent complications, such as delayed eruption, tooth displacement, crowding, root resorption of the adjacent tooth, and cystic formations.

\section{References}

1. Primosch RE (1981) Anterior supernumerary teeth--assessment and surgical intervention in children. Pediatr Dent 3: 204-215. [Crossref]

2. Mallineni SK, Kumar S (2014) Supernumerary teeth: Review of the literature with recent updates. Conference Paper Series 1-6.
3. Rajab LD, Hamdan MA (2002) Supernumerary teeth: review of the literature and a survey of 152 cases. Int J Paediatr Dent 12: 244-254. [Crossref]

4. Cassetta M, Altieri F, Giansanti M, Di-Giorgio R, Calasso S (2014) Morphological and topographical characteristics of posterior supernumerary molar teeth: An epidemiological study on 25,186 subjects. Med Oral Patol Oral Cir 19: e545-e349. [Crossref]

5. Kurt H, Suer TB, Senel B, Avsever H (2015) A retrospective observational study of the frequency of distomolar teeth in a population. Cumhur Dent $J$ 18: 335-342.

6. Arslan A, Altundal H, Ozel E (2009) The frequency of distomolar teeth in a population of urban Turkish adults: A retrospective study. Oral Radiol 25: 118-122.

7. Kaya E, Güngör K, Demirel O, Özütürk Ö (2015) Prevalence and characteristics of non-syndromic distomolars: a retrospective study. J Investig Clin Dent 6: 282-286. [Crossref]

8. Kara MÄ, Aktan AM, Ay S, Bereket C, Ažener A, et al. (2012) Characteristics of 351 supernumerary molar teeth in Turkish population. Med Oral Patol Oral Cir Bucal 17: e395-400. [Crossref]

9. Thomas SA, Sherubin E, Pillai KS (2013) A Study on the Prevalence and Characteristics of Distomolars among 1000 Panoramic Radiographs. J Indian Acad Ora Med Radiol 25: $169-172$.

10. Gopakumar D, Thomas J, Ranimol P, Vineet DA, Thomas S, Nair VV (2014) Prevalence of supernumerary teeth in permanent dentition among patients attending a dental college in South Kerala?: A pilot study. J Indian Acad Ora Med Radiol 26: $15-18$.

11. Mitsea A, Vardas E, Papachatzopoulou A, Kalfountzos G, Leventis M, Tsiklakis $\mathrm{K}$ (2015) The frequency of non-syndromic distomolar teeth in a Greek population sample? J Clinc Exp Dent 7: 589-594. [Crossref]

12. Ata-Ali F, Ata-Ali J, Peñarrocha-Oltra D, Peñarrocha-Diago M (2014) Prevalence, etiology, diagnosis, treatment and complications of supernumerary teeth. J Clin Exp Dent 6: e414-418. [Crossref]

13. Rao PV, Chidzonga MM (2001) Supernumerary teeth: literature review. Cent Afr J Med 47: 22-26. [Crossref]

Copyright: (C2017 Arandi NZ. This is an open-access article distributed under the terms of the Creative Commons Attribution License, which permits unrestricted use, distribution, and reproduction in any medium, provided the original author and source are credited. 